\title{
Supramolecular Interaction of Fullerenes with a Curved $\pi$-Surface of a Monomeric Quadruply Ring-Fused Porphyrin
}

\author{
Yuta Saegusa, ${ }^{[a]}$ Tomoya Ishizuka, ${ }^{[a]}$ Tatsuhiro Kojima, ${ }^{[b]}$ Shigeki Mori, ${ }^{[c]}$ Masaki Kawano ${ }^{[b]}$ and \\ Takahiko Kojima*[a]
}

\begin{abstract}
Molecular binding of fullerenes, $\mathrm{C}_{60}$ and $\mathrm{C}_{70}$, with the $\mathrm{Zn}$ complex of a monomeric ring-fused porphyrin derivative (2-py) as a host molecule, which has a concave $\pi$-conjugated surface, has been confirmed spectroscopically. The structures of associated complexes composed of fullerenes and 2-py have been explicitly established by $X$-ray diffraction analysis. The fullerenes in the 2:1 complexes, which consist of two 2-py molecules and one fullerene molecule, are fully covered by the concave surfaces of the two 2-py molecules in the crystal structure. In contrast, in the crystal structure of the 1:1 complex consisting of one 2-py molecule and one $\mathrm{C}_{60}$ molecule, the $\mathrm{C}_{60}$ molecule formed a $\pi-\pi$ stacked pair with a $\mathrm{C}_{60}$ molecule in the neighboring complex using a partial surface, which was uncovered by the 2-py molecule. Additionally, the molecular size of fullerene adopted significantly affects the ${ }^{1} \mathrm{H}$ NMR spectral changes and the redox properties of 2-py upon the molecular binding.
\end{abstract}

Formation of supramolecular assemblies consisting of fullerenes and porphyrins have attracted great interest from a wide range of chemists, ${ }^{[1-4]}$ because it can conduct efficient photoinduced electron transfer reactions. ${ }^{[5,6]}$ The planar structure of porphyrin and the curved surfaces of fullerenes are not well matched to

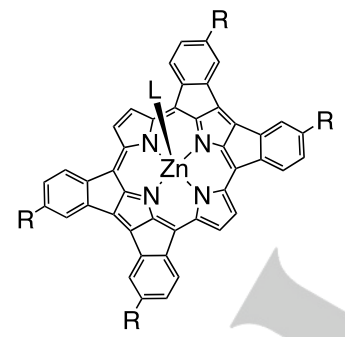

$1(\mathrm{R}=\mathrm{H}, \mathrm{L}=$ none), 1-py $(\mathrm{R}=\mathrm{H}, \mathrm{L}=$ pyridine $)$

2 ( $R=$ Mesityl, $L=$ none), 2-py $(R=$ Mesityl, $L=$ pyridine $)$

Figure 1. Molecular Structures of ZnQFP Derivatives.

[a] Y. Saegusa, Dr. T. Ishizuka, Prof. Dr. T. Kojima Department of Chemistry University of Tsukuba

1-1-1 Tennoudai, Tsukuba, Ibaraki 305-8571 (Japan)

E-mail: ishizuka@chem.tsukuba.ac.jp, kojima@chem.tsukuba.ac.jp

[b] Dr. T. Kojima, Prof. Dr. M. Kawano

Division of Advanced Materials Science

Pohang University of Science and Technology (POSTECH)

San 31, Hyoja-dong, Pohang, 790-784 (Korea)

[c] Dr. S. Mori

Department of Molecular Science, Integrated Center for Science

Ehime University

Matsuyama 790-8577 (Japan)

Supporting information for this article is given via a link at the end of the document. form strong $\pi-\pi$ interaction, and thus, the interaction between fullerenes and monomeric porphyrins is too weak to be observed in solution. ${ }^{[7]}$ Consequently, for efficient binding of fullerenes in solution, porphyrin hosts need to be dimers or higher oligomers. ${ }^{[2,3,8]}$ A concave-structured molecule with a curved surface, however, can be expected to form more stable molecular complexes with convex-shaped fullerenes on the basis of a suitable fit to gain stronger intermolecular $\pi-\pi$ interaction. ${ }^{[9]}$

Recently, we have reported the synthesis of a $\mathrm{Zn}^{\text {Il }}$ complex of a quadruply fused porphyrin (ZnQFP, 1) and elucidated that the planar structure of $\mathbf{1}$, which is most stable as suggested by DFT calculations, changes to a concave structure by axial coordination of pyridine at the zinc center. ${ }^{[10]}$ Herein, we utilize the extensively $\pi$-conjugated concave surface of a pyridinecoordinated ZnQFP derivative to recognize the convex surfaces of fullerenes.

We used a ZnQFP derivative (2) having mesityl groups at the fused benzene rings (Figure 1$)^{[11]}$ to improve the solubility for molecular binding with fullerenes, $\mathrm{C}_{60}$ and $\mathrm{C}_{70}$. At first, we determined the association constant between 2 and pyridine $\left(K_{\mathrm{py}}\right)$. UV-Vis titration experiments of 2 with pyridine in 1,2dichlorobenzene (DCB) at $298 \mathrm{~K}$ indicated the binding constant for the $1: 1$ complex as $K_{\mathrm{py}}=(2.0 \pm 0.6) \times 10^{6} \mathrm{M}^{-1}$ (See Figure S1 in the Supporting Information (SI)). The structure of the pyridine complex of 2 (2-py) was revealed by single-crystal X-ray diffraction analysis (Figure S2 in the $\mathrm{SI}$ ). The asymmetric unit included a half molecule of 2-py. In the crystal, the porphyrin core consisting of four pyrrole rings, four meso-carbons and four fused meso-benzene rings is bowl-shaped and the mean deviation of the core 48 atoms is $0.389 \AA$, which is larger than that of 1-py $(0.212 \AA) \cdot{ }^{[10]}$ The $Z n^{\prime \prime}$ center is positioned at $1.278 \AA$ above from the mean plane to the direction of the coordinated pyridine.

To confirm the interaction between 2-py and fullerenes in solution, the solution of 2-py in DCB $\left(7.5 \times 10^{-5} \mathrm{M}\right)^{[12]}$ was titrated with the solution of fullerenes in DCB $\left(1.9 \times 10^{-3} \mathrm{M}\right)$ at $298 \mathrm{~K}$ (Figure S3 in the SI). In all cases using $\mathrm{C}_{60}$ and $\mathrm{C}_{70}$, the $\mathrm{Q}$ bands of 2-py showed hypsochromic shifts. The binding constants were obtained from the titration curves based on the absorbance at $778 \mathrm{~nm}$ for $\mathrm{C}_{60}$ and that at $668 \mathrm{~nm}$ for $\mathrm{C}_{70}$, using a nonlinear least-squares regression program. ${ }^{[13]}$ Based on eqs

$$
\begin{aligned}
& 2 \text {-py }+ \text { Ful } \rightleftarrows(2-p y) \cdot(F u l) \quad ; \quad K_{1}=\frac{[(2-p y) \cdot(F u l)]}{[2-p y][F u l]} \\
& 2 \text {-py }+(2-p y) \cdot(F u l) \rightleftarrows(2-p y)_{2} \cdot(F u l) \quad ; \quad K_{2}=\frac{\left[(2-p y)_{2} \cdot(F u l)\right]}{[(2-p y) \cdot(F u l)][2-p y]} \\
& \text { 2-2-py }+ \text { Ful } \rightleftarrows(2-p y)_{2} \cdot(\text { Ful }) ; \beta_{2}=K_{1} \times K_{2}=\frac{\left[(2-p y)_{2} \cdot(\text { Ful })\right]}{[2-p y]^{2}[\text { Ful }]}
\end{aligned}
$$


a)

$$
\begin{aligned}
& \text { b) } 3 \text { eq of } C_{70} \\
& 2 \text { eq of } C_{70} \\
& 1.5 \text { eq of } C_{70} \\
& 1 \text { eq of } C_{70} \\
& 0.75 \text { eq of } C_{70} \\
& 0.5 \text { eq of } C_{70} \\
& 0.25 \text { eq of } C_{70} \\
& \quad f C_{70}
\end{aligned}
$$$$
8.3
$$$$
\begin{aligned}
& 8.2 \\
& \delta / \mathrm{ppm}
\end{aligned}
$$

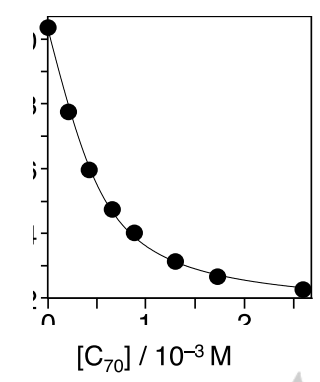

Figure 2. Left: ${ }^{1} \mathrm{H}$ NMR spectral change of 2-py in DCB- $d_{4}$ with addition of $\mathrm{C}_{60}$ (a) and $\mathrm{C}_{70}$ (b) in the presence of pyridine $\left(1.2 \times 10^{-2} \mathrm{M}\right)$ at $298 \mathrm{~K}$. Right: the fitting curves of the signal of pyrrole- $\beta$-protons.

1 and 2 , the stepwise constants, $K_{1}$ and $K_{2}$, were estimated to be $(1.1 \pm 0.1) \times 10^{4} \mathrm{M}^{-1}$ and $(1.2 \pm 0.2) \times 10^{3} \mathrm{M}^{-1}$ for $\mathrm{C}_{60}$, and $(1.3 \pm 0.1) \times 10^{4} \mathrm{M}^{-1}$ and $(2.2 \pm 0.3) \times 10^{3} \mathrm{M}^{-1}$ for $\mathrm{C}_{70}$, respectively (Table 1$)$. Therefore, the total binding constants $\left(\beta_{2}\right)$ for the complexes of QFP : fullerene $=2: 1$ were calculated to be $(1.3 \pm 0.3) \times 10^{7} \mathrm{M}^{-2}$ for $\mathrm{C}_{60}$ and $(2.9 \pm 0.2) \times 10^{7} \mathrm{M}^{-2}$ for $\mathrm{C}_{70}$, respectively (Table 1 ). As far as we know, this is the first example that the molecular binding between monomeric porphyrins and fullerenes has been demonstrated in solution. ${ }^{7,9 c]}$ Additionally, the constants are not significantly different between the cases of $C_{60}$ and $C_{70}$. Although the $K_{1}$ values are larger than the $K_{2}$ values for both $\mathrm{C}_{60}$ and $\mathrm{C}_{70}$, the differences are not large enough to clearly observe the stepwise binding from the 2:1 to $1: 1$ fashions. In fact, the Job's plots for the association between 2-py and fullerenes, obtained under the relatively concentrated conditions at $298 \mathrm{~K}$ (total concentration of 2-py and fullerenes: $1.7 \times 10^{-4} \mathrm{M}$ ), indicated the formation of the $2: 1$ complex (Figure $\mathrm{S} 4$ in the $\mathrm{SI}$ ). We also conducted the titration experiments of 2 with fullerenes in the absence of pyridine in DCB (Figure S5 in the $\mathrm{SI}$ ). As results, the addition of fullerenes brought drastic absorption changes, in comparison to the cases in the presence of pyridine. These changes probably derive from the association with fullerenes, causing structural changes of $\mathbf{2}$ from the planar form to the bowl-shaped structure to strengthen the $\pi-\pi$ interaction with fullerenes. Compound 2, however, exhibits selfaggregation in DCB in the concentration for the titration experiments $\left(7.5 \times 10^{-5} \mathrm{M}\right)$. Increasing the concentration of $\mathbf{2}$ in
Table 1. Binding constants of 2-py with fullerenes, $\mathrm{C}_{60}$ and $\mathrm{C}_{70}$, in DCB at $298 \mathrm{~K}$, obtained from a nonlinear least-squares regression analysis of the absorbance changes at $778 \mathrm{~nm}$ for $\mathrm{C}_{60}$ and $668 \mathrm{~nm}$ for $\mathrm{C}_{70}$ and ${ }^{1} \mathrm{H}$ NMR chemical shift changes of the $\beta$-pyrrole proton of 2-py.

\begin{tabular}{ccccc}
\hline fullerene & method & $K_{1} / 10^{3} \mathrm{M}^{-1}$ & $K_{2} / 10^{3} \mathrm{M}^{-1}$ & $\beta_{2} / 10^{7} \mathrm{M}^{-2}$ \\
\hline $\mathrm{C}_{60}$ & UV-Vis & $11 \pm 1$ & $1.2 \pm 0.2$ & $1.3 \pm 0.3$ \\
& ${ }^{1} \mathrm{H}$ NMR & $10 \pm 1$ & $1.2 \pm 0.1$ & $1.2 \pm 0.2$ \\
\multirow{2}{*}{$\mathrm{C}_{70}$} & UV-Vis & $13 \pm 1$ & $2.2 \pm 0.3$ & $2.9 \pm 0.2$ \\
& ${ }^{1} \mathrm{H}$ NMR & $12 \pm 1$ & $2.3 \pm 0.5$ & $2.8 \pm 0.6$ \\
\hline
\end{tabular}

DCB caused a blue shift of the Soret band; for instance, $619 \mathrm{~nm}$ at $1.4 \times 10^{-6} \mathrm{M}$ and $597 \mathrm{~nm}$ for $1.4 \times 10^{-4} \mathrm{M}$ (Figure S6 in the $\mathrm{SI})$. In contrast, the Soret band of 2-py did not show any dependence on the concentration in $\mathrm{DCB}$ in the presence of pyridine. These results indicate that compound 2 exhibits $\mathrm{H}$-type $\pi-\pi$ stacking under concentrated conditions and the pyridine coordination to give rise to deformation of the porphyrin core prevents the $\pi-\pi$ stacking. Therefore, the self-aggregation of 2 by the $\pi-\pi$ stacking disturbs the analysis of the titration experiments with fullerenes in the absence of pyridine in the solution.

For further confirmation of the association between 2-py and fullerenes in solution, ${ }^{1} \mathrm{H}$ NMR titration experiments were also performed in DCB- $d_{4}$ at $298 \mathrm{~K}$ (Figures 2, S7 and S8 in the SI). Addition of $\mathrm{C}_{60}$ caused upfield shifts of the $p-\mathrm{CH}_{3}$ groups of the peripheral mesityl groups in 2-py $\left(8.8 \times 10^{-4} \mathrm{M}\right)$ from $\delta 2.159$ ppm in the absence of $\mathrm{C}_{60}$ to $2.147 \mathrm{ppm}$ in the presence of 3 equiv of $\mathrm{C}_{60}$. Slight downfield shifts of the $\mathrm{O}-\mathrm{CH}_{3}$ groups of the mesityl groups and the pyrrole- $\beta$-protons were also observed with increasing amount of $\mathrm{C}_{60}$ (Figure 2a). The shift widths of the NMR signals of 2-py were relatively small in the titration with $\mathrm{C}_{60}$. In sharp contrast, addition of $\mathrm{C}_{70}$ to the solution of 2-py in DCB$d_{4}$ induced clear shifts of the ${ }^{1} \mathrm{H}$ NMR signals (Figures $2 \mathrm{~b}$ and $\mathrm{S} 8$ in the $\mathrm{SI}$ ). The chemical shift changes of the ${ }^{1} \mathrm{H}$ NMR signals for the $o$ - and $p-\mathrm{CH}_{3}$ groups of the mesityl groups and the $\beta$-pyrrole protons of 2-py were used to estimate the association constants, $K_{1}, K_{2}$, and $\beta_{2}$, using the nonlinear least-squares regression program (Tables 1 and S1 in the $\mathrm{SI}$ ). ${ }^{[13]}$ All of the association constants obtained from the analyses of the chemical shift changes are comparable to those obtained with UV-Vis titration experiments (see Table 1). The downfield shift of the $\mathrm{o}-\mathrm{CH}_{3}$ groups can be explained by a result of $\mathrm{CH} / \pi$ interaction with $\mathrm{C}_{70}$ and the upfield shift of the $\beta$-pyrrole protons can be ascribed to the ring current effect of aromatic $\mathrm{C}_{70}$ surfaces in the associated complexes. This explanation is well matched with the crystal structure of the 2:1 complex between 2-py and $\mathrm{C}_{70}$ (see below). In addition, the downfield shifts of the $p-\mathrm{CH}_{3}$ groups indicate the decrease of the electron densities of the mesityl groups upon formation of the associated complexes between 2-py and $\mathrm{C}_{70}$, probably caused by charge-transfer (CT) interaction from 2-py to $\mathrm{C}_{70}$ (see the electrochemical studies described below). On the other hand, the shift widths of the ${ }^{1} \mathrm{H}$ NMR signals for the $\mathrm{o}-\mathrm{CH}_{3}$ groups and the $\beta$-pyrrole protons for the $\mathrm{C}_{60}$ complexes are modest, which can be elucidated by considering the small volume of $\mathrm{C}_{60}$ relative to the cavity composed of the $\mathrm{o}-\mathrm{CH}_{3}$ 
a)

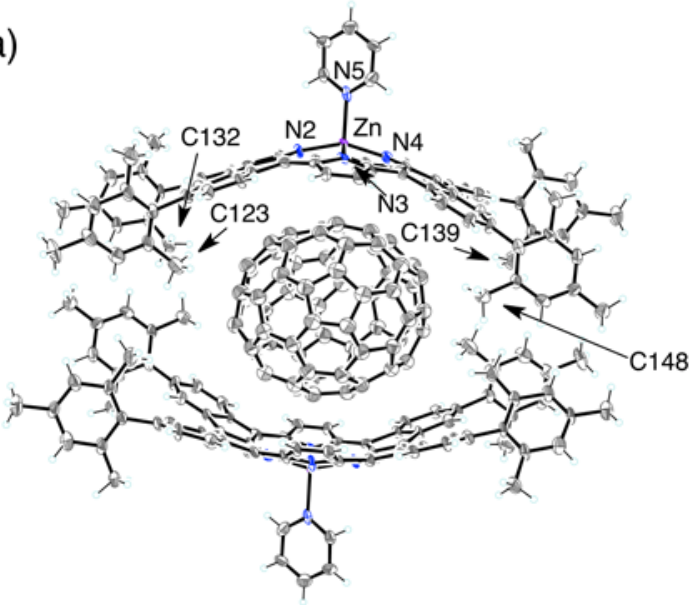

b)

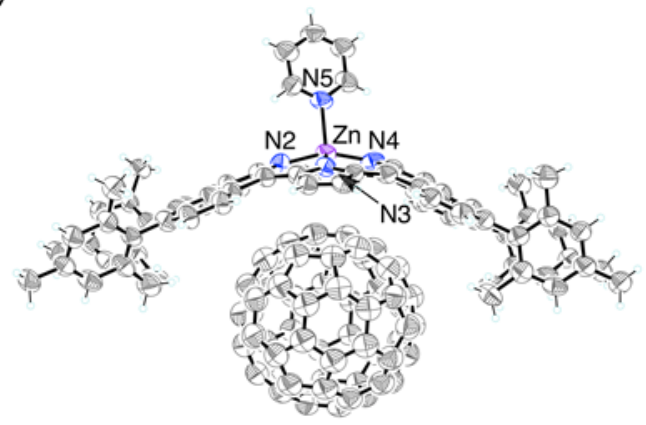

Figure 3. ORTEP drawings of crystal structures of (2-py) $)_{2} \cdot \mathrm{C}_{70}$ (a) and 2-py. $\mathrm{C}_{60}$ (b). The thermal ellipsoids are drawn with $50 \%$ probability. One of the disordered pair of the fullerenes is shown for clarity.

groups of 2-py. The small shift of the pyrrole- $\beta$-Hs is probably ascribed to that the $\mathrm{C}_{60}$ molecule is not located on the top of the $\beta$ - $\mathrm{Hs}$ in the solution due to the smaller size than that of $\mathrm{C}_{70}$.

The structures of supramolecular assemblies of 2-py with fullerenes have been explicitly revealed by single-crystal X-ray diffraction analysis (Figure 3). The single crystal of the 2:1 complex between 2-py and $\mathrm{C}_{70}$ was obtained with slow evaporation of the solvent from the toluene solution (Figure 3a).
The $\mathrm{C}_{70}$ molecule, which exhibited crystallographic disorder in the crystal, was covered with two molecules of 2-py and the longer axis of $\mathrm{C}_{70}$ was tilted to 2-py by $29.4^{\circ}$. The concave surface of 2-py and the convex surface of $\mathrm{C}_{70}$ are well matched each other to form strong $\pi-\pi$ interaction. On the other hand, the single crystal obtained from the solution of 2-py and $\mathrm{C}_{60}$ in DCB in the presence of methanol vapor as a poor solvent gave a preliminary crystal structure of the 2:1 complex (Figure S9 in the $\mathrm{SI})$. Interestingly, alteration of the poor solvent to the acetonitrile vapor gave a single crystal of the $1: 1$ complex with $C_{60}$ (Figure $3 b$ ), where the half sphere of $\mathrm{C}_{60}$ was covered with a molecule of 2-py. The uncovered surface of $\mathrm{C}_{60}$ was used to form a $\pi-\pi$ stacked pair of the two $\mathrm{C}_{60}$ molecules, in which the $\mathrm{C}-\mathrm{C}$ bonds between a six- and five-membered rings came closer and the closest $\mathrm{C} \ldots \mathrm{C}$ distance in the paired $\mathrm{C}_{60}$ molecules was $2.89(4)$ $\AA$. The porphyrin cores in all associated structures determined are more distorted relative to that of free 2-py: The mean deviations of the core 48 atoms of 2-py are $0.584,0.571$, and $0.502 \AA$ for the $1: 1$ and $2: 1$ complexes with $C_{60}$ and the 2:1 complex with $\mathrm{C}_{70}$, respectively. This increase in the degree of the curved distortion for the porphyrin structures in the associated complexes should be induced to strengthen the $\pi$ - $\pi$ interaction with the fullerenes. ${ }^{[14]}$ As results, the distances between the planes of 2-py and fullerenes are $3.30,3.23$, and $3.23 \AA$, for the 1:1 and 2:1 complexes with $\mathrm{C}_{60}$ and the $2: 1$ complex with $\mathrm{C}_{70}$, respectively. Additionally, the molecular size of $\mathrm{C}_{70}$ is matched to the cavity provided by four $\mathrm{o}-\mathrm{CH}_{3}$ groups of 2-py and three among the four $\mathrm{CH}_{3}$ groups are close enough in the distances to form $\mathrm{CH} / \pi$ interaction with $\mathrm{C}_{70}$; the distances from $\mathrm{C}_{70}$ to the four $0-\mathrm{CH}_{3}$ groups, which are represented by $\mathrm{C} 123, \mathrm{C} 132, \mathrm{C} 139$, and C148 in Figure 3a, are 3.33(3) 3.81(4), 4.95(3), and 3.64(4) Å, respectively. On the other hand, the size of $\mathrm{C}_{60}$ is small for the cavity and thus the $C_{60}$ molecule both in the 1:1 and 2:1 complexes is located on a side of the two fused rings of 2-py, and in consequence, the distances from $\mathrm{C}_{60}$ to two $o-\mathrm{CH}_{3}$ groups are in the range of the $\mathrm{C}-\mathrm{H} \cdots \pi$ distances (ca. $3.8 \AA$ ), whereas the other two show longer distances from the $\mathrm{C}_{60}$ molecule (ca. $4.2 \AA$ ) (See the $\mathrm{SI}$ ).

The association between 2-py and fullerenes affect the redox potentials of 2-py and fullerenes in DCB (Table 2 and Figures $\mathrm{S} 10$ and $\mathrm{S} 11$ in the $\mathrm{SI}$ ). The cyclic and differential pulse voltammograms (CV and DPV) of 2-py in DCB $\left(1.3 \times 10^{-3} \mathrm{M}\right)$ exhibited two oxidation waves at +0.11 and $+0.52 \mathrm{~V}$ vs $\mathrm{Fc} / \mathrm{Fc}^{+}$

Table 2. Redox potentials of 2-py and fullerenes, $\mathrm{C}_{60}$ and $\mathrm{C}_{70}$, in DCB in the presence of $0.2 \mathrm{M} \mathrm{TBAP}$ and $0.012 \mathrm{M}$ pyridine at $298 \mathrm{~K}$.

\begin{tabular}{|c|c|c|c|c|c|c|c|}
\hline & \multicolumn{7}{|c|}{$E_{1 / 2} / \mathrm{V} v s \mathrm{Fc} / \mathrm{Fc}^{+}$} \\
\hline & Por $^{2-} /$ Por $^{-}$ & Por-/Por & Por/Por ${ }^{*+}$ & Por $+/$ Por $^{2+}$ & $\mathrm{Ful}^{\cdot 3-} / \mathrm{Ful}^{2-}$ & $\mathrm{Ful}^{2-} / \mathrm{Ful}^{--}$ & Ful-/Ful \\
\hline 2-py & $-1.58^{a}$ & $-1.28^{\mathrm{a}}$ & $+0.11^{[a]}$ & $+0.52^{[a]}$ & - & - & - \\
\hline $\mathrm{C}_{60}$ & - & - & - & - & -1.97 & -1.48 & -1.07 \\
\hline $2-p y+C_{60}$ & $-1.60^{a}$ & -1.20 & +0.16 & $+0.53^{[a]}$ & -2.01 & -1.50 & -1.06 \\
\hline$\Delta E, \mathrm{~V}$ & +0.02 & +0.08 & +0.05 & +0.01 & -0.04 & -0.02 & +0.01 \\
\hline $\mathrm{C}_{70}$ & - & - & - & - & -1.79 & -1.37 & -1.00 \\
\hline $2-p y+C_{70}$ & -1.57 & -1.26 & +0.13 & +0.52 & -1.89 & -1.44 & -1.06 \\
\hline$\Delta E, \mathrm{~V}$ & +0.01 & +0.02 & +0.02 & +0.00 & -0.06 & -0.07 & -0.06 \\
\hline
\end{tabular}

[a] The values were obtained from DPV. 
and two reduction waves at -1.28 and $-1.58 \mathrm{~V}$ vs $\mathrm{Fc} / \mathrm{Fc}^{+}$in the presence of pyridine $\left(1.2 \times 10^{-2} \mathrm{M}\right)$ and tetrabutyl-ammmonium perchlorate (TBAP, $0.2 \mathrm{M}$ ) as an electrolyte at $298 \mathrm{~K}$. The CVs and DPVs of $\mathrm{C}_{60}$ and $\mathrm{C}_{70}$ measured under the same conditions displayed three reduction waves at $-1.06,-1.50$ and $-2.01 \mathrm{~V}$ vs $\mathrm{Fc} / \mathrm{Fc}^{+}$for $\mathrm{C}_{60}$, and $-1.00,-1.37$ and $-1.79 \mathrm{~V}$ vs $\mathrm{Fc} / \mathrm{Fc}^{+}$for $\mathrm{C}_{70}$, respectively. The 2:1 mixture of 2-py $\left(1.3 \times 10^{-3} \mathrm{M}\right)$ and the $\mathrm{C}_{70}$ $\left(6.4 \times 10^{-4} \mathrm{M}\right)^{[15]}$ showed the redox waves with significant shifts (Table 2). The redox potentials of 2-py were positively shifted in the association with $\mathrm{C}_{70}$, whereas those of $\mathrm{C}_{70}$ exhibited negative shifts. The tendencies of the potential shifts can be accounted for the charge-transfer (CT) interaction from 2-py to the fullerenes. ${ }^{[16]}$ As results of the $C T$ interaction, the electron density of 2-py decreased, whereas that of fullerenes increased; this makes reduction of fullerenes and oxidation of 2-py harder in the associated complexes. The degree of potential shifts of $\mathrm{C}_{70}$ was larger than that of 2-py, because of difference between degree of associated $\mathrm{C}_{70}$ and that of 2-py; ${ }^{[15]}$ totally,72\% of 2-py formed complexes with $C_{70}$, whereas $97 \%$ of $C_{70}$ participated in complexation with 2-py. The 2:1 mixture of 2-py $\left(1.3 \times 10^{-3} \mathrm{M}\right)$ and $\mathrm{C}_{60}\left(6.4 \times 10^{-4} \mathrm{M}\right)$ showed the redox waves with modest shifts. This can be explained on the basis of the fact that the first redox potential of $\mathrm{C}_{60}$ is lower than that of $\mathrm{C}_{70}$, therefore the $\mathrm{CT}$ interaction from 2-py to the $\mathrm{C}_{60}$ is weaker in comparison with the case of $\mathrm{C}_{70}$.

In conclusion, the association equilibriums between the mononuclear $\mathrm{Zn}^{\prime \prime}$ complex of a QFP derivative, 2-py, and fullerenes, $C_{60}$ and $C_{70}$, have been fully investigated spectroscopically and electrochemically. The concave surface of 2-py is well matched to the convex surface of fullerenes for strong $\pi-\pi$ interaction, especially for $\mathrm{C}_{70}$. In addition, the $\mathrm{CH} / \pi$ interaction of the $o-\mathrm{CH}_{3}$ groups of the mesityl groups and the CT interaction assisted the association between 2-py and fullerenes. The molecular sizes of the fullerenes significantly affected the ${ }^{1} \mathrm{H}$ NMR spectral changes and redox potential shifts of 2-py. The structures of the associated complexes have been explicitly elucidated by the $\mathrm{X}$-ray diffraction analysis. The fullerenes are fully covered by the concave surfaces of two 2-py molecules in the 2:1 complexes. In contrast, in the crystal structure of the 1:1 complex of $\mathrm{C}_{60}$, the $\mathrm{C}_{60}$ molecules formed a $\pi-\pi$ stacked pair using the partial surface, uncovered by one 2-py molecule.

\section{Acknowledgements}

We appreciate Prof. Shigehisa Akine (Kanazawa University) for providing a nonlinear least-squares regression program. Prof. Takeshi Akasaka (University of Tsukuba) is also acknowledged for the gift of $\mathrm{C}_{70}$. The $\mathrm{X}$-ray diffraction studies with synchrotron radiation were performed at the PF-AR (NW2A Beamline) of the High Energy Accelerator Research Organization (KEK) (proposal no. 2014G008). This work was supported by Grantsin-Aid (Nos. 20108010, 22750118, and 24245011) from Japan Society of the Promotion of Science (JSPS).

Keywords: porphyrin $\bullet$ fullerene $\bullet$ molecular binding $\bullet$ crystal structure $\bullet$ electrochemistry
[1] a) D. Canevet, E. M. Pérez, N. Martín, Angew. Chem. 2011, 123, 9416 9427; Angew. Chem. Int. Ed. 2011, 50, 9248-9259; b) P. D. W. Boyd, C A. Reed, Acc. Chem. Res. 2005, 38, 235-242; c) K. Tashiro, T. Aida Chem. Soc. Rev. 2007, 36, 189-197.

[2] a) K. Tashiro, T. Aida, J.-Y. Zheng, K. Kinbara, K. Saigo, S. Sakamoto K. Yamaguchi, J. Am. Chem. Soc. 1999, 121, 9477-9478; b) J.-Y Zheng, K. Tashiro, Y. Hirabayashi, K. Kinbara, K. Saigo, T. Aida, S Sakamoto, K. Yamaguchi, Angew. Chem. 2001, 113, 1909-1913 Angew. Chem. Int. Ed. 2001, 40, 1857-1861; c) Y. Shoji, K. Tashiro, T. Aida, J. Am. Chem. Soc. 2004, 126, 6570-6571; d) M. Yanagisawa, K. Tashiro, M. Yamasaki, T. Aida, J. Am. Chem. Soc. 2007, 129, 11912 11913; e) F. Hajjaj, K. Tashiro, H. Nikawa, N. Mizorogi, T. Akasaka, S Nagase, K. Furukawa, T. Kato, T. Aida, J. Am. Chem. Soc. 2011, 133, 9290-9292.

[3] a) P. D. W. Boyd, M. C. Hodgson, C. E. F. Rickard, A. G. Oliver, L. Chaker, P. J. Brothers, R. D. Bolskar, F. S. Tham, C. A. Reed, J. Am Chem. Soc. 1999, 121, 10487-10495; b) D. Sun, F. S. Tham, C. A. Reed, L. Chaker, P. D. W. Boyd, J. Am. Chem. Soc. 2002, 124, 66046612; c) A. Hosseini, S. Taylor, G. Accorsi, N. Armaroli, C. A. Reed, P. D. W. Boyd, J. Am. Chem. Soc. 2006, 128, 15903-15913.

[4] a) H. Nobukuni, Y. Shimazaki, F. Tani, Y. Naruta, Angew. Chem. 2007 119, 9133-9136; Angew. Chem. Int. Ed. 2007, 46, 8975-8978; b) J. Zhang, X. Zheng, R. Jiang, Y. Yu, Y. Li, H. Liu, Q. Li, Z. Shuaic, Y. Li, RSC Adv. 2014, 4, 27389-27392.

[5] a) G. Bottari, O. Trukhina, M. Ince, T. Torres, Coord. Chem. Rev. 2012 256, 2453-2477; b) G. Bottari, G. de la Torre, D. M. Guldi, T. Torres, Chem. Rev. 2010, 110, 6768-6816; c) S. Fukuzumi, T. Kojima, J. Mater Chem. 2008, 18, 1427-1439.

[6] a) H. Nobukuni, Y. Shimazaki, H. Uno, Y. Naruta, K. Ohkubo, T. Kojima S. Fukuzumi, S. Seki, H. Sakai, T. Hasobe, F. Tani, Chem. Eur. J. 2010 16, 11611-11623; b) B. Grimm, J. Schornbaum, C. M. Cardona, J. D van Paauwe, P. D. W. Boyd, D. M. Guldi, Chem. Sci. 2011, 2, 15301537; c) T. Kamimura, K. Ohkubo, Y. Kawashima, H. Nobukuni, Y Naruta, F. Tani, S. Fukuzumi, Chem. Sci. 2013, 4, 1451-1461.

[7] X. Fang, Y.-Z. Zhu, J.-Y. Zheng, J. Org. Chem. 2014, 79, 1184-1191.

[8] a) G. Gil-Ramírez, S. D. Karlen, A. Shundo, K. Porfyrakis, Y. Ito, G. A D. Briggs, J. J. L. Morton, H. L. Anderson, Org. Lett. 2010, 12, 3544 3547 ; b) J. Song, N. Aratani, H. Shinokubo, A. Osuka, J. Am. Chem. Soc. 2010, 132, 16356-16357; c) A. R. Mulholland, C. P. Woodward, S. J. Langford, Chem. Commun. 2011, 47, 1494-1496.

[9] a) E. M. Pérez, N. Martín, Chem. Soc. Rev. 2008, 37, 1512; b) E. M. Pérez, L. Sánchez, G. Fernández, N. Martín, J. Am. Chem. Soc. 2006 128, 7172-7173; c) I. Sáanchez-Molina, C. G. Claessens, B. Grimm, D. M. Guldi, T. Torres, Chem. Sci. 2013, 4, 1338-1344.

[10] T. Ishizuka, Y. Saegusa, Y. Shiota, K. Ohtake, K. Yoshizawa, T. Kojima, Chem. Commun. 2013, 5, 5939-5941.

[11] The synthetic details are reported elsewhere: Y. Saegusa, T. Ishizuka, K. Komamura, S. Shimizu, H. Kotani, N. Kobayashi, T. Kojima, submitted.

[12] The solutions of $\mathbf{2}$ for the titration experiments with fullerenes included pyridine $\left(7.9 \times 10^{-5} \mathrm{M}\right)$, and thus, over $96 \%$ of 2 in the solution were coordinated with pyridine, based on the association constant $\left(K_{\mathrm{py}}\right)$ between 2 and pyridine, at $298 \mathrm{~K}$.

[13] K. Hirose, J. Incl. Phen. Macrocycl. Chem. 2001, 39, 193-209.

[14] A. L. Litvinov, D. V. Konarev, A. Yu. Kovalevsky, I. S. Neretin, P. Coppens, R. N. Lyubovskaya, Cryst. Growth Des. 2005, 5, 1807-1819.

[15] In the 2:1 mixed solution of 2-py $\left(1.3 \times 10^{-3} \mathrm{M}\right)$ and $\mathrm{C}_{60}\left(6.4 \times 10^{-4} \mathrm{M}\right)$ for the electrochemical studies at $298 \mathrm{~K}, 2$-py : $\mathrm{C}_{60}=2: 1$ and 1:1 complexes co-existed and the percentages based on 2-py are $44 \%$ for the $2: 1$ complex and $22 \%$ for the $1: 1$ complex and the percentages based on $\mathrm{C}_{60}$ are $47 \%$ for the $2: 1$ complex and $47 \%$ for the $1: 1$ complex, respectively. In the solution of 2-py $\left(1.3 \times 10^{-3} \mathrm{M}\right)$ and $\mathrm{C}_{70}(6.4$ $\times 10^{-4} \mathrm{M}$ ), the percentages based on 2-py are $55 \%$ for the 2:1 complex and $17 \%$ for the $1: 1$ complex and the percentages based on $\mathrm{C}_{70}$ are $60 \%$ for the $2: 1$ complex and $37 \%$ for the $1: 1$ complex, respectively.

[16] K. Tashiro, T. Aida, J. Incl. Phen. Macrocycl. Chem. 2001, 41, 215-217. 


\section{COMMUNICATION}

Planar

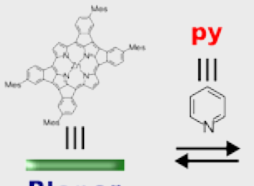

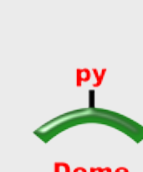

Dome
Fullerenes
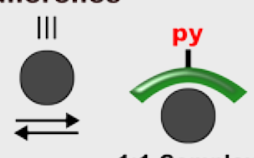

$\rightleftarrows$

1:1 Complex

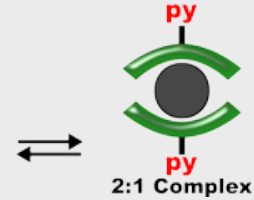

Molecular binding of fullerenes, $\mathrm{C}_{60}$ and $\mathrm{C}_{70}$, with a monomeric $\mathrm{Zn}$ " complex of ringfused porphyrin derivative (2-py), having a concave $\pi$-conjugated surface induced by the axial coordination, has been confirmed by spectroscopies and X-ray diffraction analysis. The molecular sizes of the fullerenes significantly affect the ${ }^{1} \mathrm{H}$ NMR spectral changes and the redox properties of 2-py upon molecular binding.
Y. Saegusa, T. Ishizuka, * T. Kojima, S. Mori, M. Kawano, T. Kojima*

Page No. - Page No.

Supramolecular Interaction of Fullerenes with a Curved $\pi$-Surface of a Monomeric Quadruply Ring-Fused Porphyrin 


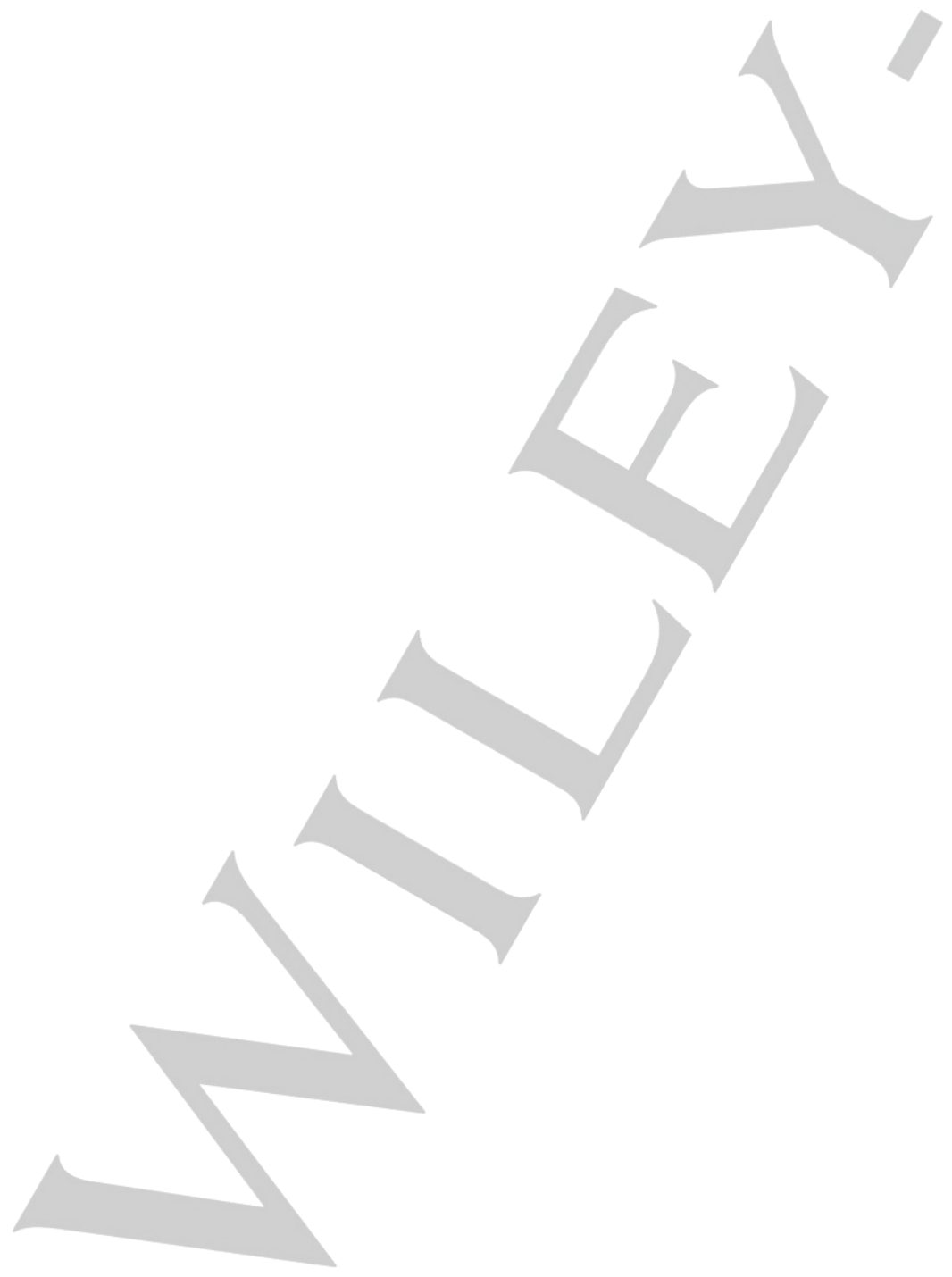

